\title{
Research on Statistical Index System of Cross-border E-commerce
}

\author{
Jun Wang \\ School of Economics and Management \\ Shandong Youth University of Political Science \\ Jinan, China 250103
}

\begin{abstract}
With the development of information technology, cross-border e-commerce has become an important force of promoting economic and social development. However, the statistics of cross-border e-commerce development is always a difficult problem. At present, the domestic and foreign research on the statistical indicators of cross-border ecommerce is still very weak. There is no uniform method. Research on statistics index system of cross-border ecommerce has important practical significance for doing a better job in cross-border e-commerce statistics. On the basis of defining the concept of cross-border e-commerce, this paper expounds statistics present situation and problems of crossborder e-commerce in China, and preliminarily establishes a set of system of cross-border e-commerce statistical index system. Finally, this paper puts forward countermeasures and suggestions for doing a better job in cross-border e-commerce statistics.
\end{abstract}

Keywords-cross-border e-commerce; statistical index system; key indicators

\section{INTRODUCTION}

As the main branch of e-commerce, cross-border ecommerce plays an important role in the development of China's import and export trade.In recent years, due to the impact of domestic and international trade environment, the development of traditional foreign trade has apparently slowed, while the development of cross-border ecommerce has maintained a high level of growth. In 2016, the overall transaction scale of cross-border e-commerce in China (including retail and B2B) reached 6 trillion and 300 billion yuan [1].

However, the statistics of cross-border e-commerce development is always a difficult problem. As a new means of exchange, cross-border e-commerce has penetrated into all walks of life. How many companies have in the use of crossborder e-commerce, how to use, there is no unified method. The main reason for this phenomenon is that the definition of cross-border e-commerce is different, the statistical methods are very different, and the data of cross-border e-commerce is difficult to obtain [2]. Therefore, the statistical work of cross-border e-commerce is also increasingly mentioned on

Fund Project: key project of art and science in 2017 in Shandong province, The study on the development and countermeasures of foreign cultural trade in Shandong Province by the Belt and Road Initiative (Item number: 201706349) the important agenda. How to conduct the statistical and quantitative evaluation of the rapid development of crossborder e-commerce is of great significance for the healthy and sustainable development of cross-border e-commerce in china.

\section{PRESENT SituATION OF CROSS-BORDER E- COMMERCE IN CHINA}

\section{A. The Development of Cross-border E-commerce}

In recent years, cross-border e-commerce in China has developed rapidly, especially in the transaction scale online of online shopping market and import retail trade. As shown in "Fig. 1", in 2016, the scale of online shopping market in China reached 5 trillion yuan, compared with 2015 increased by $30.5 \%$, and the growth level is relatively stable. The development of online shopping industry in China has matured. The e-commerce providers have begun to developing rural e-commerce and cross-border online shopping, opening innovative e-commerce field [3].

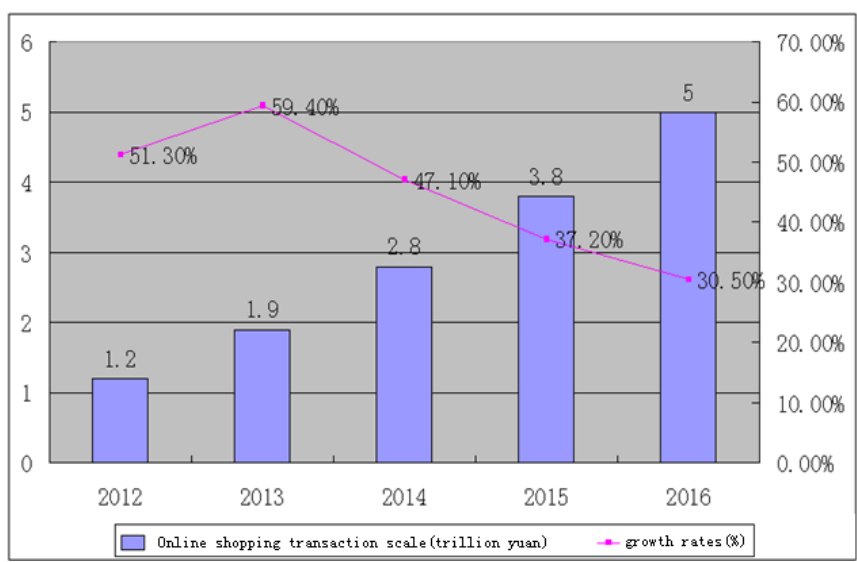

Fig. 1. The scale of online shopping market in China in 2012-2016 years.

Since 2014, because of liberating retail policy of ecommerce in China, a large number of start-up companies and domestic e-commerce providers have entered into retail markets for e-commerce import. As shown in "Fig. 2", in 2016 years, the market size has reached 2498.1 billion yuan; the growth rate was $85.6 \%$. In the next few years, the retail markets for e-commerce import will remain healthy and stable development. 


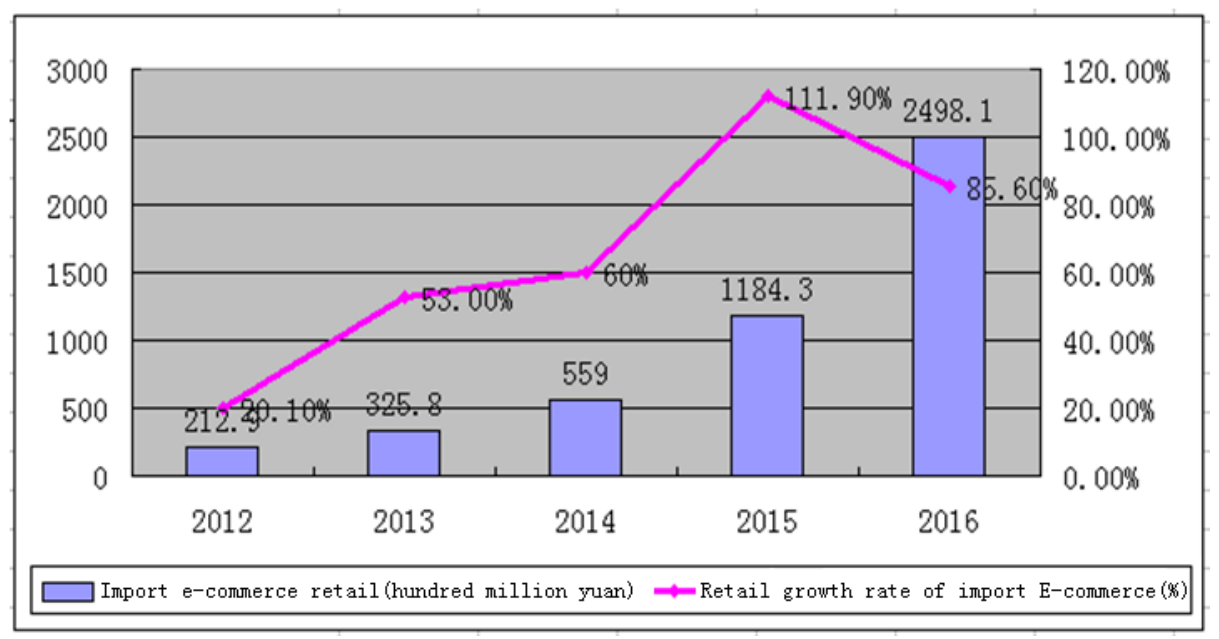

Fig. 2. The transaction scale and growth rate of the retail markets for e-commerce import in China in 2012-2016 years.

\section{B. Statistical Status of Cross-border E-commerce}

In December 2016, China put forward "the 13th FiveYear development planning of e-commerce", and suggest that "e-commerce is a new network of economic activity and the important force of promoting the Internet + "[4]. From the macro perspective, this definition is helpful for the whole society to attach great importance to the development of e-commerce. But from the point of view of statistical application, this definition is difficult to define the scope of e-commerce applications and brings great difficulty to the statistics of cross-border e-commerce which is the main branch of e-commerce.

At the same time, "planning" pointed out "further explore the docking data resources of e-commerce in leading enterprise, build e-commerce economic operation monitoring platform, research and propose e-commerce development index". Thus, the provincial e-commerce, especially crossborder e-commerce statistics system has not yet unified nationally, leading to data statistics of cross-border ecommerce in China is difficult to achieve precision. Therefore, it is urgent to study the establishment of a standardized cross-border e-commerce statistics system, make clear statistical caliber and unify statistical standards, in order to play the guiding role of statistics comprehensively and effectively.

\section{Problems to Be Solved in Cross-border E-commerce Statistics}

In order to solve the statistical problems better in the development of cross-border e-commerce, we should focus on the following four aspects:

First of all, cross-border e-commerce statistical work involves a wide range. Chinese officials should bring crossborder e-commerce statistics into the national statistical work plan.

Secondly, the statistical standards of cross-border ecommerce are inconsistent, which may lead to different statistical results. Therefore, the relevant departments should join the efforts to study and formulate cross-border e- commerce statistics standards. The most important of these standards is the establishment of statistical indicators.

Thirdly, taking into account the differences in the actual situation, a detailed statistical system should be established from the perspective of the region and the enterprise. In this way, cross-border e-commerce statistics not only serve the formulation of strategic decisions on the whole macro level, but also take measures according to local conditions.

Finally, because of difficulties in obtaining and grasping indicators of cross-border e-commerce transaction, the accuracy of the data is worrying. Wrong filling and leakage occur frequently.

\section{STATISTICAL INDEX SYSTEM OF CROSS-BORDER E- COMMERCE}

\section{A. Overall Design of Statistical Index System of Cross- border E-commerce}

In this paper, the design of cross-border e-commerce statistics index system is composed of three parts: readiness, application level and influence.

1) The ready status: This part mainly reflects the Internet service providers, telecommunication service providers, telephone line conditions, the use of the Internet way, the obstructing factors of cross-border e-commerce, the number of employees who grasp the information technology and the number of Internet hosts.

2) Application level: This part mainly reflects the amount and frequency of Internet usage, the expectation of using Internet, the popularity of Internet, the number and value of cross-border e-commerce transactions.

3) Impact: This part mainly reflects the impact of crossborder e-commerce on the performance of the company (cost, profit, time, etc.) and the promotion of the national economy.

With the passage of time, especially the improvement of the level of information, the whole society's demand for three indicators of cross-border e-commerce is also changing. 
In fact, the subject of behavior in a country's economy (enterprise, government, family, etc.) can be at different levels of development. At a stage of development, indicators of cross-border e-commerce can often be applied in the same or slightly different ways at another stage.

\section{B. Factors to Be Considered in Cross-border E-commerce Statistics}

At present, in the process of cross-border e-commerce statistics and designing index system in our country, we can consider the following several important factors:

1) The development level of information technology: The development of cross-border e-commerce depends on the rapid development of information and communication technology. Application of information and communication technology mainly includes the development level of information and communication technology, construction and quality of information network system, development of software and laws, software related to information and communication technology and service of communication technology. Communication technology covers all aspects of cross-border e-commerce operation, is the guarantee of the operation of cross border E-commerce today [5].

2) Cross-border e-commerce transactions: Like traditional business models, the most important indicator of cross-border e-commerce development is the amount of transactions. The amount of cross-border e-commerce transactions directly reflects the level of cross-border ecommerce development. The impetus of cross-border ecommerce is that cross-border e-commerce can promote the increase of enterprise trade volume. At present, both international organizations and various countries regard trading volume as the core index of cross-border ecommerce development. Therefore, the index of crossborder e-commerce transactions should be the key indicators.

3) Environmental construction of cross-border $e$ commerce: The development of cross-border e-commerce in China is still in its infancy. Cross-border e-commerce will be widely carried out, in addition to strengthening the construction of network infrastructure and information technology, the external environment of cross-border ecommerce should be strengthened. The external environment of cross-border e-commerce includes legal environment, transaction environment and the social credit system. These external environments play an important role in ensuring the development of cross-border e-commerce and stimulating the interest of enterprises and citizens in cross-border e-commerce.

\section{Framework Design of Statistical Index System for Cross- border E-commerce}

Combined with the development status and research status of cross-border e-commerce in China, and referring to the relevant theoretical research and practical experience at home and abroad, two kinds of indicators are designed, including readiness index and usage status index of cross- border e-commerce. It is used to measure and evaluate crossborder e-commerce in different countries and regions.

Before the statistics of cross-border e-commerce, it is very useful to investigate the necessary preparations for cross-border e-commerce applications in countries or regions. This can be done by the network hardware infrastructure, users' basic use of cross-border e-commerce infrastructure, talent reserves of cross-border e-commerce and national policies on cross border e-commerce development.

With the good foundation of cross-border e-commerce development, it is necessary to make a statistical analysis of the use of cross-border e-commerce, including usage density of cross-border e-commerce, transactions of cross-border ecommerce and electronic level in the process of transaction.

\section{Major Issues in Selecting Key Statistical Indicators of Cross-border E-commerce}

Choosing the key statistical indicators correctly is the core link in the establishment of cross- border e-commerce statistical model. The error of key index selection will not only result in huge data, not easy to calculate, but also affect the final statistical effect. The major issues in selecting key statistical indicators of cross-border e-commerce are as follows:

Firstly, it is necessary to correctly understand and grasp statistical theory and economic operation law implied in the statistical phenomena. This is the basis for the correct choice of explanatory variables. Because of the difference economic environment between cross-border e-commerce and traditional exchanges, the selection of key statistical indicators must be different.

Secondly, it is necessary for reasonable assumptions. The statistical model should reflect the objective of economic activity, but this kind of reflection can't cover and contain everything. This requires reasonable assumptions to remove minor relationships and simplify and abstract the model.

Thirdly, the selection of key statistical indicators must take into account the availability of data. Therefore, the selection of key statistical indicators must be in the statistical indicators system, which is reliable data source.

\section{COUNTERMEASURE AND SUGGESTIONS ON CROSS- BORDER E-COMMERCE STATISTICS}

In order to do a better job in cross-border e-commerce statistics and provide the reference basis for the government decision-making and enterprise development, this paper puts forward some preliminary countermeasures and suggestions.

\section{A. Establishing a Scientific Cross-border E-commerce Statistical System}

There are several principles should be followed when perfecting the statistical system of cross-border e-commerce. The first one is standardization. To ensure the calculation methods, classification catalogues, and statistical codes adopted in the cross-border e-commerce statistical survey. The second one is simplicity. Make sure you are easy to 
understand when you set your index, giving prominence to the key points. The third one is controllable. Ensure that the implementation of the statistical investigation system, the data acquisition channels, and the data quality assurance is controllable.

\section{B. Improving Statistical Work Methods of Cross-border E- commerce}

It should do a good job in cross-border e-commerce statistics work, firstly, we should refine training. Through careful training, let the enterprise statisticians understand requirements and specifications of each index. Secondly, we should pay attention to the explanation. Explanation is the supplement of enterprise reporting cross-border e-commerce data, and it is an indispensable part of completing the reporting task comprehensively. Thirdly, it is necessary to strengthen responsibility. Grassroots and statistics personnel need to have strong sense of responsibility and ensure the accuracy and reliability of cross border e-commerce statistics.

\section{Reforming Investigation Mode of Cross-border E- commerce}

It is suggested that the government statistics departments adjust the report mode of cross-border e-commerce reports, and further clarify the "subject" responsibility of relevant professional at all levels. All related departments should be responsible for e-commerce report. Service industry at all levels is responsible for the comprehensive collection, reporting, using and developing of data. Only in this way can we ensure the true and reliable quality of cross-border ecommerce statistics.

\section{Doing Well the Basic Work of Cross-border E- commerce Statistics}

First of all, optimize the report platform. At present, "a direct reporting platform" is not stable. During the reporting period, enterprises often can't login platform or can't display the report. This situation directly dampened the enthusiasm of the enterprise statements, but also increased the difficulty of the statistical department to promote the report. Therefore, the statistical department should increase the strength of the hardware construction of the reporting platform, optimize the software environment of the reporting platform, ensure the stable operation of the reporting platform, and ensure the smooth development of the statistical work. Secondly, increase grassroots forces. At present, there are few statisticians in basic service industry, but many reports are responsible for them. Therefore, it is urgent to increase the power of grassroots statisticians to ensure the quality of the source data of cross-border e-commerce statistics.

\section{CONCLUSION}

This paper defines the concept of cross-border ecommerce theoretically, establish a cross-border e-commerce statistics index system, selects key indicators and lays a foundation for using statistical model to measure the amount of e-commerce transactions. This paper puts forward a series of countermeasures and suggestions to cross-border ecommerce statistics.

The deficiencies and prospects of this article is how do ecommerce transactions predict the economic development of a region, which is one of the important significance of crossborder e-commerce statistics. Further exploration is needed in conjunction with relevant data.

\section{REFERENCES}

[1] Goldmanis M. E-commerce and the Market Structure of Retail Industries [J]. The Economic Journal, 2010(6):651-682.

[2] Asosheh A,Shahidi-Nejad H,Khodkari H.A model of a localized cross-border e-commerce[J]. I-Business, 2012(4):136-145.

[3] Osterwalder A,Pigneur Y.An e-Business Ontology for Modeling eBusiness [R]. 15th Bled Electronic Commerce Conference,Bled slovenia, 2002.

[4] Gomez-Herrera,Estrella.The drivers and impediments for crossborder e-commerce in the EU [J]. Information Economics \& Policy. 2014(28):83-96.

[5] An Ontology-Based Information Retrieval Model for Vegetables ECommerce [J]. Journal of Integrative Agriculture, 2012(05):800-807. 